\title{
Notes on the Stomach Contents of a Juvenile Sleepy Lizard, Tiliqua rugosa (Gray 1825), Killed by an Eastern Brown Snake, Pseudonaja textilis (Duméril, Bibron, and Duméril 1854) in South Australia
}

\author{
Gerrut Norval $^{1 *}$, Jessica Clayton ${ }^{1}$, Robert D. Sharrad ${ }^{1}$, and Michael G. Gardner ${ }^{1,2}$
}

${ }^{1}$ College of Science and Engineering, Flinders University, Adelaide, South Australia, Australia (norv0003@flinders.edu.au) ${ }^{2}$ Evolutionary Biology Unit, South Australian Museum, North Terrace Adelaide 5000, South Australia, Australia, (michael.gardner@flinders.edu.au)

Photographs by the senior author.

L izards are a very diverse group of vertebrates that inhabit and utilize a variety of habitats and niches; that their diets vary dramatically is not surprising. Only a few species have adaptations, such as colic valves and elongated intestines, that enable them to be mainly herbivorous (i.e., $>90 \%$ of the diet consists of plant material; Cooper and Vitt 2002). Most lizards are carnivorous, but many are facultative omnivores that will consume some plant material (e.g., Pianka and Vitt 2003). The Sleepy Lizard, Tiliqua rugosa (Gray 1825), which is endemic to the southern parts of Australia (Cogger 2014), is an example of such an omnivorous species. These relatively large skinks (Scincidae) opportunistically feed on invertebrates and even carrion (Fig. 1), but feed primarily on flowers (Fig. 2), fruit (Fig. 3), and leaves of a variety of native and introduced plant species (Yeatman 1988; Henle 1990; Dubas and Bull 1991). Our understanding of the diet of T. rugosa stems largely from observations of adult lizards or individuals whose age class was not specified, so the diet of juveniles is relatively poorly understood. Herein we describe the stomach contents of a juvenile T. rugosa, with notes on dietary items of adult lizards from the same locality.

At 1135 h on 20 September 2017, GN noticed an adult Eastern Brown Snake, Pseudonaja textilis (Duméril, Bibron, and Duméril 1854) on the side of a dirt road in the Mid

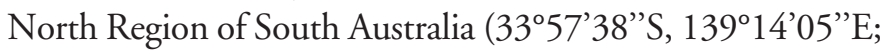
211 m elev.; datum: WGS84). Upon closer inspection, he found that the snake was starting the process of ingesting a juvenile T. rugosa (SVL $173 \mathrm{~mm}$; tail length $40 \mathrm{~mm}$; body mass $94 \mathrm{~g}$ ). However, the presence of the observer disturbed the snake and it fled after releasing the already dead lizard.
The lizard (Fig. 4) was collected and dissected to examine its digestive tract contents. The stomach was filled with leaves, a few flower buds, and pods of Ward's Weed, Carrichtera annua (L.) DC, in various advanced stages of digestion plus a few fragments of an unidentifiable forb. The only non-plant material observed was the remains of a beetle.

During the 2017 field season (mid-August to midDecember), 34.4\% (129) of the Sleepy Lizards we encountered $(n=375)$ were observed feeding. SVLs of these lizards ranged from 205 to $380 \mathrm{~mm}$ (mean $\pm \mathrm{SD}=318 \pm 30.9 \mathrm{~mm}$ ), so most were adults. Although they were feeding on a variety of food items (Table 1), in $49.7 \%$ of the instances where the food item could be identified they were parts of $C$. annua. Yeatman (1988) examined the scats of three juvenile (less than 3 months old) T. rugosa and found that the contents resembled those of adult lizards. Our observation therefore provides additional support for the conclusion that the juveniles feed on the same types of dietary items as the adults. Although some observations about the diet of wild Tiliqua scincoides also have suggested that juveniles and adults have similar diets (Yeatman 1988), this behavior does not apply to all species in the subfamily Egerniinae. In Egernia, juveniles usually are more insectivorous, whereas adults tend to be herbivorous (Chapple 2003). The apparent lack of a dietary shift in T. rugosa is most likely due to the fact that this species is an opportunistic omnivore that usually inhabits xeric environments, so individuals of all age classes will feed on the most frequently encountered food items. Empirical studies into the extent of competition between the different age classes in $T$. rugosa populations are therefore warranted. 


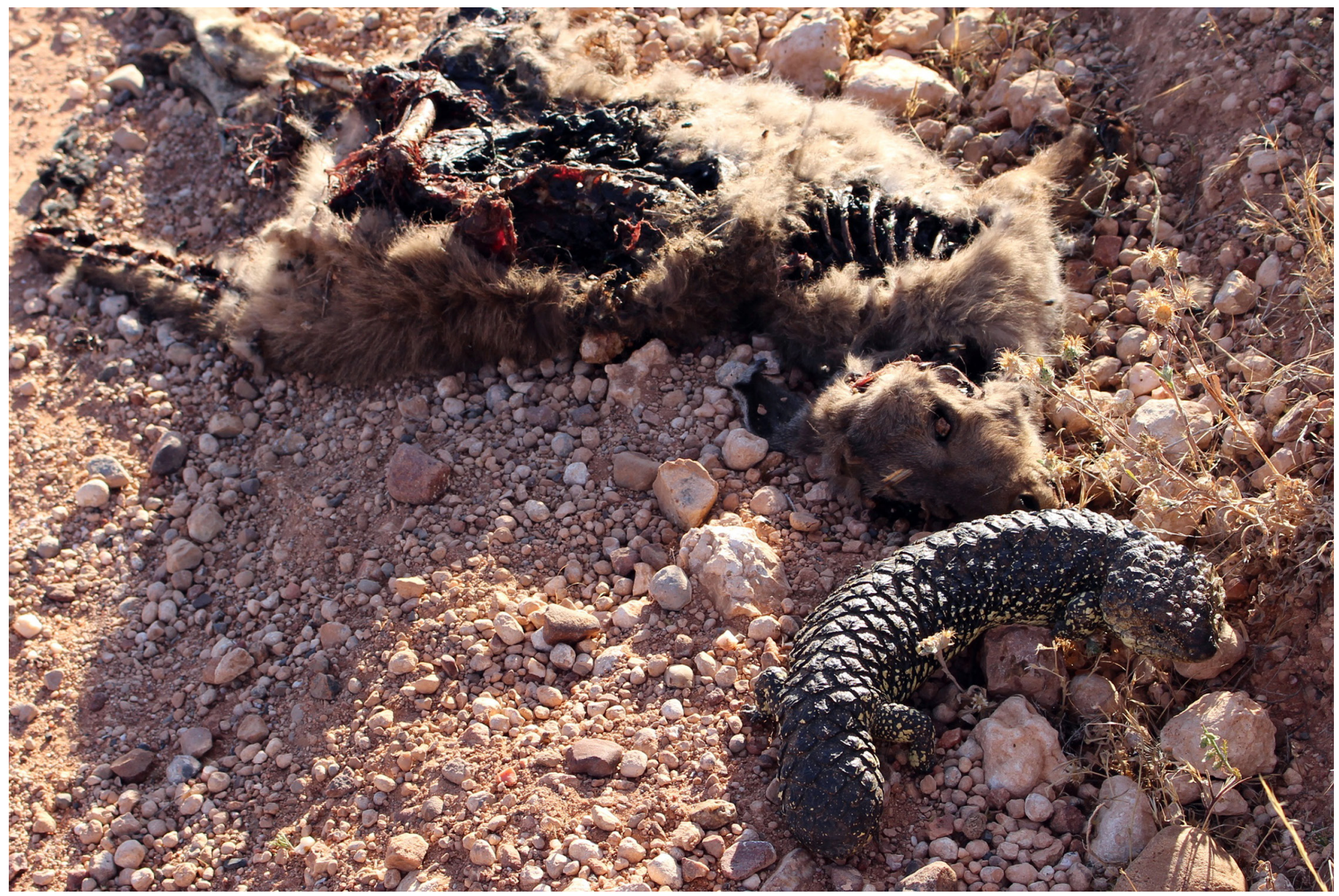

Fig. 1. A Sleepy Lizard (Tiliqua rugosa) that was feeding on the carcass of a Western Grey Kangaroo (Macropus fuliginosus).
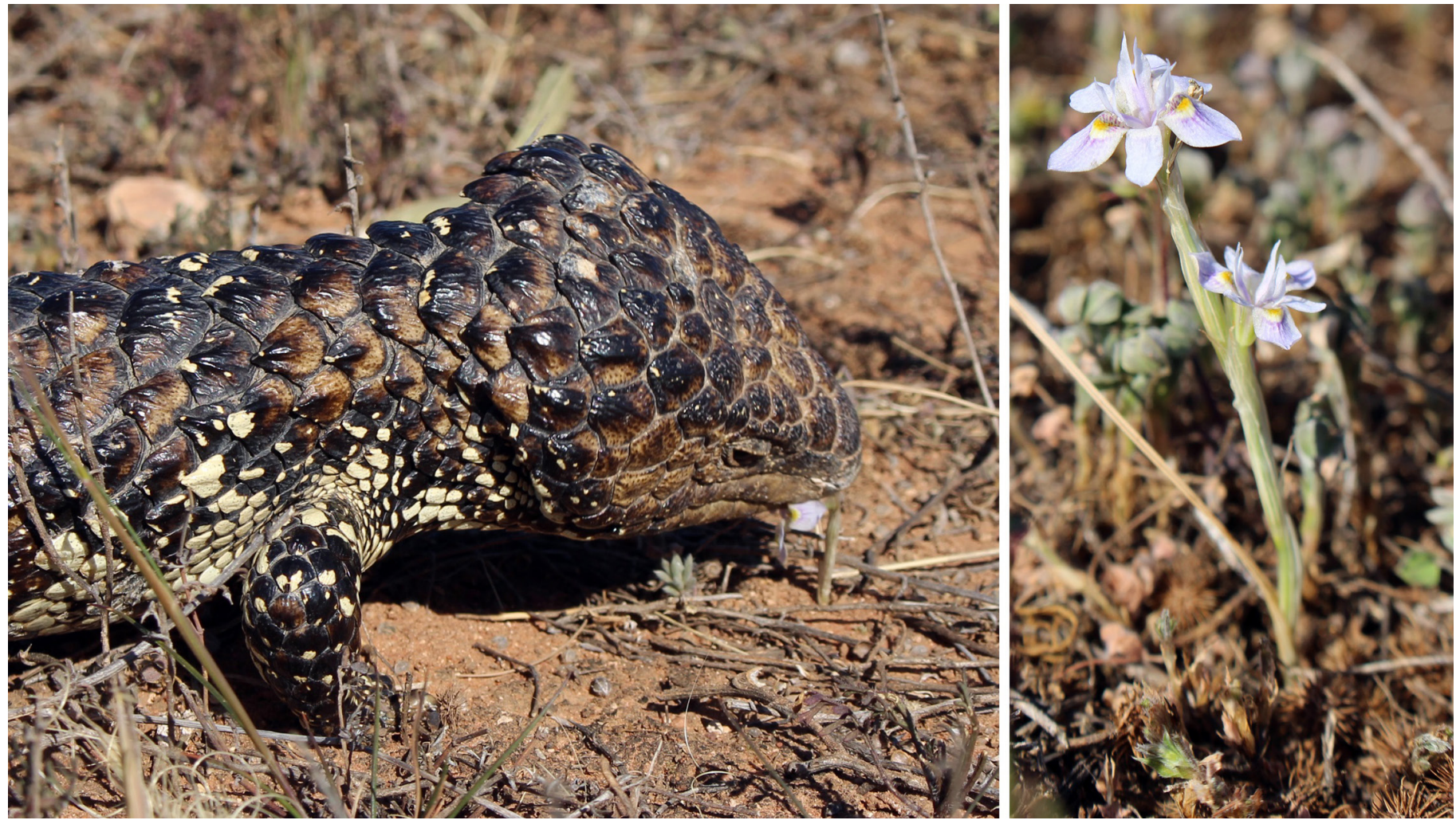

Fig. 2. A Sleepy Lizard (Tiliqua rugosa) eating the flower of a Thread Iris (Moraea setifolia) (inset on the right). 

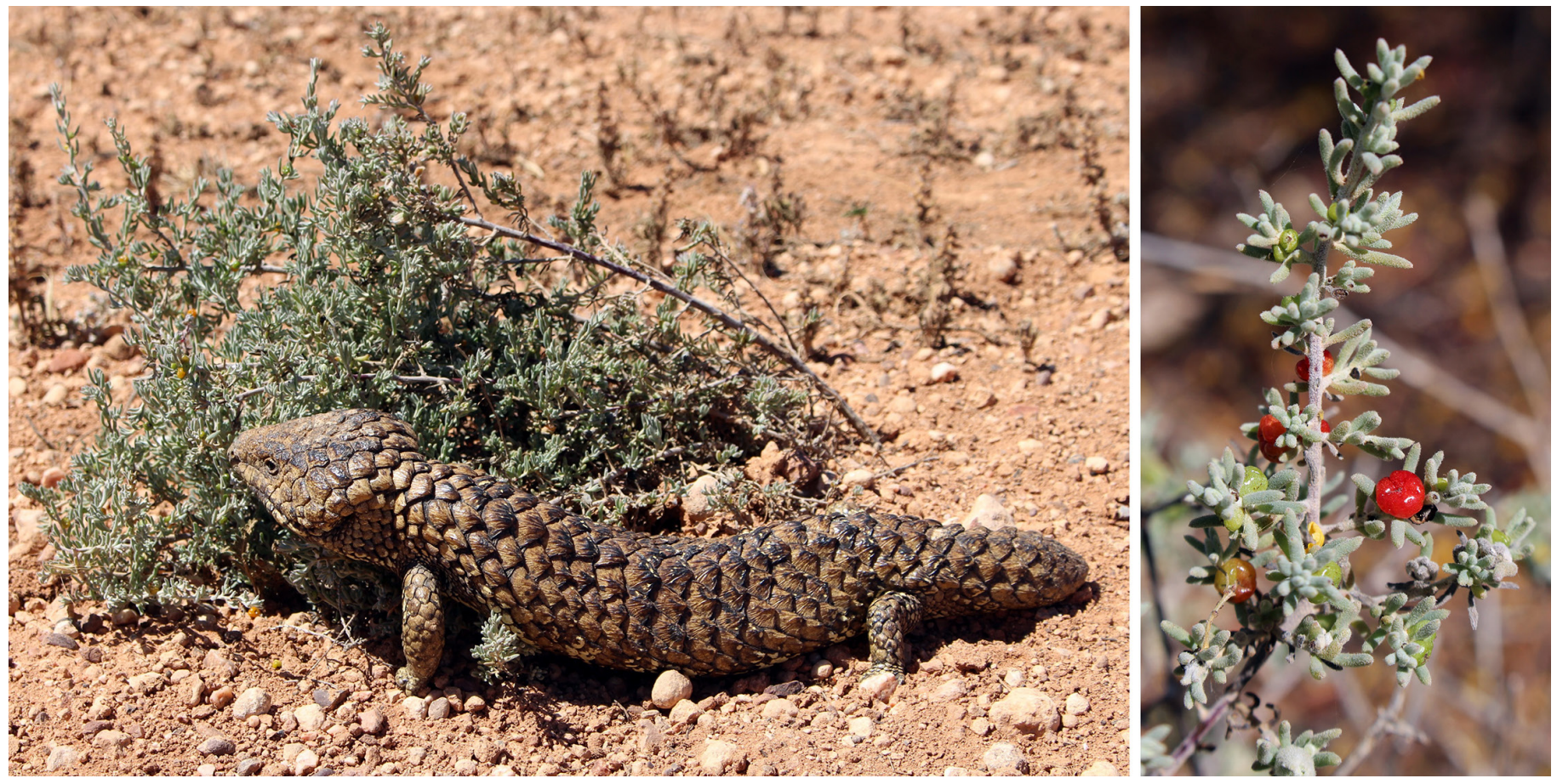

Fig. 3. A Sleepy Lizard (Tiliqua rugosa) eating the fruit of a Ruby Saltbush (Enchylaena tomentosa) (inset on the right).

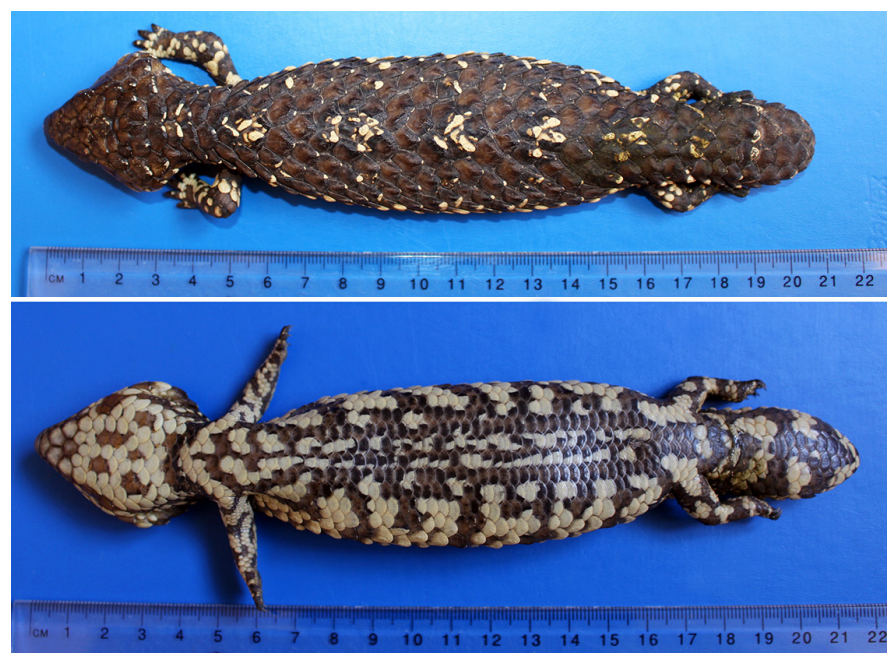

Fig. 4. A dorsal (top) and ventral (bottom) view of the juvenile Sleepy Lizard (Tiliqua rugosa) described herein prior to being dissected. The shape of the abdomen and tail suggests that it was not malnurished.

\section{Acknowledgements}

The main observation presented herein was made by the senior author while conducting surveys as part of his doctoral research, which was partly funded in 2017 by a grant from the Royal Society of South Australia. Clearance for the research was granted by the Animal Welfare Committee of Flinders University (No.: E454/17) and the Department of Environment, Water and Natural Resources of the Government of South Australia (Permit No.: A23436-25).
Table 1. Plant and animal material observed in 2017 as dietary items of the Sleepy Lizard (Tiliqua rugosa) at the study site near Mt. Mary in the Mid North Region of South Australia.

\begin{tabular}{ll} 
Species & Note \\
\hline Ward's Weed (Carrichtera annua) & $\begin{array}{l}\text { flowers, leaves, } \\
\text { and pods }\end{array}$ \\
\hline Grassy Bindweed (Convolvulus remotus) & flowers and leaves \\
\hline Paterson's Curse (Echium plantagineum) & leaves \\
\hline Ruby Saltbush (Enchylaena tomentosa) & fruit \\
\hline Berrigan (Eremophila longifolia) & flowers \\
\hline Little Bur Clover (Medicago minima) & flowers and leaves \\
\hline Sugarwood (Myoporum platycarpum) & flowers \\
\hline Wild Sage (Salvia verbenaca) & flowers and leaves \\
\hline California Pepper Tree (Schinus molle) & fruit \\
\hline Tangled Sida (Sida intricata) & leaves \\
\hline Wooly New Holland Daisy (Vittadinia gracilis) & leaves \\
\hline Westerrn Grey Kangaroo (Macropus fuliginosus) & carrion \\
\hline
\end{tabular}

\section{Literature Cited}

Chapple, D.G. 2003. Ecology, life-history, and behavior in the Australian scincid genus Egernia, with comments on the evolution of complex sociality in lizards. Herpetological Monographs 17: 145-180.

Cogger, H.G. 2014. Reptiles and Amphibians of Australia. 7th ed. CSIRO Publishing, Collingwood, Victoria, Australia.

Cooper, W.E. and L.J. Vitt. 2002. Distribution, extent, and evolution of plant 
consumption by lizards. Journal of Zoology 257: 487-517.

Dubas, G. and C.M. Bull. 1991. Diet choice and food availability in the omnivorous lizard, Trachydosaurus rugosus. Wildlife Research 18: 147-155.

Henle, K. 1990. Notes on the population ecology of the large herbivorous lizard, Trachydosaurus rugosus, in arid Australia. Journal of Herpetology 24: 100-103.
Pianka, E.R. and L.J. Vitt. 2003. Lizards: Windows to the Evolution of Diversity. University of California Press, Berkley.

Yeatman, E.M. 1988. Resource Partitioning by Three Congeneric Species of Skink (Tiliqua) in Sympatry in South Australia. Unpublished Ph.D. Thesis, Flinders University, Adelaide, South Australia. 